\title{
"Rabeno" de Emilia Pardo Bazán: mito y reflexión didáctica sobre la violencia sexual
}

\author{
Patricia Carballal Miñán \\ (UNIVERSIDADE DA CORUÑA) \\ patricia.carballal@udc.es
}

(recibido xullo/2010, revisado outubro/2010)

RESUMEN: En esta colaboración se estudia el cuento "Rabeno" de Emilia Pardo Bazán, en el que la escritora narra el terror que producen las incursiones de un potencial agresor sexual en una aldea gallega. A lo largo de nuestro estudio analizamos cómo el mismo personaje es visto como un ente fabuloso por la comunidad aldeana -que logra, con su propio código de la justicia acabar con él- y como un demente por los personajes ajenos a esta comunidad.

PALABRAS CLAVE: Emilia Pardo Bazán, análisis, "Rabeno", violencia sexual, comunidad aldeana, comunidad científica, justicia.

ABSTRACT: In this article, we are studying Rabeno’s short story by Emilia Pardo Bazán. The writer narrates the horror that occur in a Galician village where a potencial sexual offender appears. Throughout our study we analyzed how the same character is seen in two different ways: on the one hand, the characters outside of this community look at him as a madman, and the other hand, the village community looks at him as a fabulous being, which manages to kill him with its own code of justice.

KEY WORDS: Emilia Pardo Bazán, analysis, "Rabeno" sexual violence, village community, scientific community, justice.

Varios son los textos en los que Emilia Pardo Bazán denuncia lo que hoy se denomina "violencia de género". Preocupada por la situación de la mujer de su época, que era víctima, entre otros muchos abusos, de la violencia masculina, no dudó en utilizar su pluma para acusar este problema. Desde la atalaya de su serie "La Vida Contemporánea" de La Ilustración Artística de Barcelona, censuró en repetidas ocasiones los maltratos, ataques y ultrajes que sufrían las mujeres y que asiduamente llenaban las páginas de sucesos de los periódicos ante la indiferencia de la sociedad y de las autoridades. Además puso de manifiesto, a este respecto, la injusticia con la que eran juzgados los perpetradores de los abusos -en muchas ocasiones asesinos de mujeres- que resultaban impunes la mayoría de las veces a consecuencia de un sistema legal insuficiente a la hora de proteger y amparar a la población femenina ${ }^{\mathrm{I}}$.

\footnotetext{
I “La Vida Contemporánea”, 23/04/1906 (Pardo Bazán 2005: 311); “Como en las cavernas”, 16/09/1901 (Pardo Bazán 2005: 194); “Reflexiones. Zola”, 20/10/1902 (Pardo Bazán 2005: 222); “La Vida Contemporánea”, 22/12/1902 (Pardo Bazán 2005: 226); “La Vida Contemporánea”, 22/07/1901 (Pardo Bazán 2005: 190); “Ensaladilla”, 24/06/1901 (Pardo Bazán 2005: 137); “La Vida Contemporánea”, 29/07/1907 (Pardo Bazán 2005: 344). Ruiz-Ocaña Dueñas hace un estudio pormenorizado del tema en su estudio dedicado a La Vida Contemporánea (Ruiz-Ocaña Dueñas 2004a: 222-226).
} 
También en sus novelas siguió denunciando este mismo problema. Los lectores somos testigos de las brutales situaciones que sufren algunos de sus personajes femeninos, como la paliza que el zapatero Antiojos propina a su hija menor en La Piedra Angular y que acaba con su vida (Ruiz-Ocaña Dueñas 2004b: 186), la lluvia de golpes que el marqués descarga contra Sabel en Los pazos de Ulloa o el ataque que Lucía sufre por parte de Artegui en Un viaje de novios.

Pero donde quizá podamos hablar de un "corpus" de textos que reflejen esta situación de violencia e injusticia insostenible -la misma que sufrimos en los inicios del siglo XXI- es en su obra cuentística. Los numerosos relatos escritos por la condesa, que en la mayoría de las ocasiones ocupaban las páginas de periódicos y revistas de mayor circulación, se convirtieron en el vehículo idóneo para que Pardo Bazán mostrase a los lectores un universo femenino en el que reinaban el miedo, la indefensión y la brutalidad y que muchas veces era trasunto del mundo real en el que vivía la autora de Un destripador de antaño. Algunos de estos cuentos, como por ejemplo "El indulto", en el que el narrador pone de manifiesto el estado de pánico en el que vive Antonia tras ser amenazada de muerte por su marido, constituyen verdaderas obras maestras del género. También el temor hacia una terrible vida conyugal y la violencia psicológica reaparecen en otros relatos como "El encaje roto" o "El revólver". Y como ya ocurriera en el caso de las novelas, también varios cuentos versan sobre el maltrato físico, en muchas ocasiones acaecido en el seno de la pareja, como sucede en "Sin Pasión" que es objeto de estudio por parte de la profesora Pilar Couto (2010-2011: 71-96) en este mismo volumen. Este relato, en el que el personaje de Juan Vela mata al dueño de la casa en la que se hospeda por haberle dado este último una brutal paliza a su mujer, comparte con el cuento "Feminista" -que también analiza en estas páginas la profesora Araceli Herrero (2010-2011: 57-70)- un motivo: en ambos casos los personajes, bien el del maltratador, en el caso de "Sin Pasión", bien el del marido que humilla a su esposa en el caso de "Feminista", reciben un castigo como respuesta a su reprochable conducta. Batalladora contra las leyes que dejaban casi impunes a los agresores y desprotegían a sus víctimas, Pardo Bazán nos presenta dos casos en los que la venganza o el castigo son ejercidos por otros medios, ajenos a la justicia. En ninguno de los relatos son las leyes o las autoridades quienes ponen fin al acoso femenino, sino que son los propios protagonistas los que toman la ley por su mano.

Esta situación vuelve a repetirse en el cuento que será objeto de este breve estudio, "Rabeno"2. En este texto, Pardo Bazán ha fijado su mirada en un tipo concreto de violencia: la sexual ${ }^{3}$, si bien no perpetrada en el seno de una pareja, sino en el de una comunidad amenazada por la presencia de un agresor. Por tanto, el castigo será ejecutado por sus propios miembros, quienes pondrán fin al asedio del personaje de acuerdo a su propio código y sentido de la justicia.

\footnotetext{
2 Este cuento fue publicado el 08/10/1912 en La Ilustración Española y Americana de Madrid.

3 La violencia sexual en varios lugares de su obra. Recordemos, por ejemplo el ataque que sufre Doña Milagros por parte de su asistente en la novela homónima o la violación perpetrada por Gaspar de Montenegro a Miss Annie en La Sirena Negra. También se alude al abuso sexual en El Cisne de Vilamorta, en la que la maestra Leocadia Otero tiene un hijo tras haber sido ultrajada por su propio tío.
} 
El argumento del relato es el siguiente: un médico llega a una aldea gallega para atender a su paciente, Don Agustín, y se encuentra con una "mociña" que se asusta de él. Una vez el médico se identifica como tal, la joven aclara que el origen de su miedo radica en haber confundido al doctor con el "Rabeno", suerte de ente "que mata a la gente y le saca los untos" además de que a las jóvenes les "abre [..] la barriga, que es una vergüenza para las mociñas nuevas", según informa la chica. El médico, intrigado tras dejar a la rapaza, se entrevista con su paciente, quien le informa que el maléfico personaje no es más que un pobre loco que ronda la aldea y que se acerca "con cierto aire de conquistador a las mocitas" y al que los aldeanos ven como la encarnación del mítico ser. Convencido por las palabras de D. Agustín, el doctor se dispone a salir del pueblo tras decidir que al día siguiente avisará a las autoridades para que ingresen al pobre loco en el asilo. Pero después de esperar inútilmente a su cochero y salir en su busca, descubre que los aldeanos han dado captura al supuesto "Rabeno" tras haber intentado agredir a una de las jóvenes de la aldea, la hija del tabernero. Ante la impotencia del médico, propinan una brutal paliza al desconocido y finalmente, arrojan su cuerpo, casi inerte, al mar.

Como en varias ocasiones se ha estudiado, en la cuentística de Pardo Bazán abundan las figuras de la tradición popular galaica. Hay que destacar aquí la vinculación de la escritora con la "Sociedad del Folk-lore Gallego", de la que fue Presidenta desde su creación en 1884. A través de esta sociedad la escritora se puso en contacto con un importantísimo legado cultural popular que no dudó en aprovechar para su creación literaria culta. En el Cuestionario de dicha asociación, que establece las bases de los estudios que debían seguir sus miembros, hay un apartado dedicado a recoger las "Creencias y supersticiones populares de Galicia" (Cuestionario 1994: 26-31). Tal vez bajo este epígrafe los miembros del "Folk-lore" pudieron atesorar la creencia en el "Rabeno", suposición que está reforzada si tenemos en cuenta que la que parece ser la primera alusión de la mítica figura en un texto literario, corrió de la mano de uno de sus socios, Antonio de La Iglesia, quien la incluyó en un relato publicado en Galicia Humorística en mayo de 1888 y titulado "A rexuba de San Lorenzo" $^{\prime 4}$. Las connotaciones negativas relativas a la violencia y al deseo sexual de esta figura folclórica, están ya perfiladas en este texto, si bien es Pardo Bazán la primera escritora que introduce la figura en la literatura acompañada de todas las características y atribuciones de la tradición popular ${ }^{5}$. También los etnógrafos se han

\footnotetext{
4 En este texto, Antonio de la Iglesia narra que los lunes de Pascua se reunían todos los murmuradores de Santiago para increpar a sus vecinos. Uno de ellos averguenza a un caminante, dirigiéndose a él con las siguientes palabras "Ai tede-lo Rabeno (...). Non te arrimes moito a esa inocente rapaza, que eres capaz de matala co alento".

5 Años después, en 1943, también Wenceslao Fernandez Flórez aludirá al "Rabeno" como uno de los personajes que pueblan la fraga de Cecebre en El bosque animado: "Nadie puede decir exactamente por qué, y hasta quizá lo negaría, pero todos los espíritus sienten una turbación cuando les envuelve la fraga; los niños no pasan por sus linderos, las muchachas la atraviesan con un recelo palpitante porque se acuerdan por la noche de ese fantasma alto, blanco, que es la Estadea, y por el día el sátiro al que los poetas han hecho funerales desde que nadie volvió a verle en las montañas polvorientas de Grecia ni en las florestas de Italia, pero que vive misteriosamente refugiado con el extraño nombre de Rabeno en las umbrías de Galicia, sin más cronista que las mozas que hablan de él entre risas y miedos, en la penumbra de la cocina...”. (Fernández Flórez1943:40).
} 
ocupado de recoger la existencia de este ente fabuloso. En el apartado "Etnografía. Cultura espiritual" de Vicente Risco, incluido en la Historia de Galicia dirigida por Otero Pedrayo, el estudioso alude y recoge la mítica existencia del "Rabeno" (Risco 1962: 304), del que también habla Carré Alvarellos en sus Apuntes para una mitología popular gallega (s. a.: 19-20). Pero para encontrar una definición precisa del personaje basta con acercarse al diccionario de Eladio Rodríguez González, quien lo define como:

Ente imaginario, a manera de sátiro, forjado por la imaginación de las mozas aldeanas. El Rabeno, según la legendaria creencia de las mozas aldeanas, recorría las corredoiras solitarias y los apartados lugares de nuestros montes y campiñas. Hay quienes describen este ser fantástico como un hombre pálido, alto y delgado; y lo único cierto es que debido a la fama de que le ha rodeado la opinión vulgar campesina, algunos viandantes a quienes el temor femenil tomó por el Rabeno, se han visto en riesgo, perseguidos por los vecinos del contorno, alarmados por los gritos de socorro dados por la joven que se creyó próxima a ser víctima de los lascivos deseos del ficticio sujeto. (Rodríguez González 1958-1962: tomo 3, 222) ${ }^{6}$

El relato de Pardo Bazán narra, precisamente, una de estas situaciones, si bien lo hace creando un marco específico y escogiendo cuidadosamente las figuras de su narración. Recoge este mito de la tradición popular gallega y lo inserta en la literatura culta de finales de siglo XIX, es decir, lo literaturiza. Se propone crear un cuento en el que se ponga de manifiesto la reacción de una comunidad ante el miedo que generan las apariciones de un agresor sexual en potencia, al que las mozas ven como al sobrenatural "Rabeno" y al que una parte de los portadores de la ciencia de la época consideran un loco, un enfermo, que debía ser tratado como tal. En primer lugar la escritora ha situado la historia y el discurso del cuento, en un espacio muy particular: una aldea gallega, verdadero trasunto de cualquier otra, contemporánea a Emilia Pardo Bazán. Buena parte de la narrativa de la condesa se desarrolla en escenarios rurales como este, hasta el punto de que incluso podríamos aventurar la idea de que este espacio -que posee además unas coordenadas temporales precisas-funciona en la literatura de la escritora como un verdadero cronotopo, igual de efectivo que, por ejemplo, la ciudad provinciana para Flaubert"

Pero la aldea gallega no es sólo un lugar en el mapa imaginario de los mundos de ficción de la autora de Los pazos de Ulloa, es también el reflejo de un espacio simbólico y cultural, un escenario según las palabras del antropólogo Lisón Tolosana "desde el que se vive la existencia", circunscrito a su propio lebesnwelt y que tiene

\footnotetext{
6 Si bien la figura del "Rabeno" pudiera estar vinculada con el sátiro pagano, como Eladio Rodríguez González, Emilia Pardo Bazán y Wenceslao Fernandez Flórez señalan, podríamos también apuntar que la creencia en demonios que tomaban cuerpo humano para tener relaciones sexuales con mujeres viene también de muy antiguo y estaba muy extendida, tal y como podemos comprobar leyendo la obra del autor cántabro Martino Delrío (1616): Disquisitionum magicarum. Libri sex Venetiis, Vincentium Florinum, pp. 146-150.

7 Sin embargo, esta idea debe ser matizada con un estudio que integre toda la cuentística de la escritora, cuyo desarrollo debemos postergar para otra ocasión.
} 
su propia cultura, compartida por todos sus miembros y en la que se incluyen tanto un sistema de creencias, mitos y tradiciones (Lisón Tolosana 1971: 113) como un particular sentido de la justicia y de la moral. Y dentro de ese sistema de creencias, se halla la de la figura del "Rabeno", personaje en el que los aldeanos -y en especial las mujeres- condensaban el miedo atávico hacia la violencia sexual.

En los límites espaciales de este lugar, durante el tiempo del discurso del relato, Pardo Bazán ha hecho coincidir a dos grupos de personajes que se organizan de acuerdo a unas características mentales y culturales concretas y que verán y juzgarán la aparición del agresor que ronda la aldea desde perspectivas muy diferentes. De un lado, convive una pequeña comunidad aldeana: una "mociña", un tabernero, la mujer de este y su hija, además de una turba furiosa que hace su aparición al final del relato. Todos ellos comparten la misma visión de mundo, el mismo sentido de la moral y la justicia y las mismas coordenadas culturales en cuyo sistema el elemento femenino ha forjado, debido a un miedo atávico hacia los crímenes sexuales, el mito de un ser sobrenatural -obsérvese que la "mociña" lo compara con "la Compaña"con el que identifican a cualquier desconocido que se acerque a ellas con fines libidinosos.

Junto a esta pequeña comunidad convive un personaje que aunque vecino, se aleja radicalmente de los demás habitantes del pueblecillo porque ni su cultura, ni su visión de mundo coinciden con las de los aldeanos. Don Agustín, el paciente a quien el médico visita, hace gala de una formación científica y literaria ajena a la cultura popular y al sistema de la aldea. Compartiendo sus razonamientos y su particular idiosincrasia se halla también el doctor. Ambos forman un segundo grupo cuyo pensamiento científico se aleja mucho del de los aldeanos.

Pero, realmente, si indagamos en la estructura del relato veremos que no son solo las características psicológicas las que separan a las dos esferas de personajes, sino que también se diferencian por su función dentro de la acción de la trama. Dado que todo el discurso acaece dentro de los límites de la aldea, es solamente el grupo formado por los propios aldeanos, con su particular sentido de la justicia, el que intervendrá para poner fin a las visitas del agresor que aterroriza a las mujeres de su comunidad, mientras que el médico y su paciente quedan excluidos de la acción.

Sin embargo, el punto de vista de la narración -para la cual Pardo Bazán ha elegido hábilmente la figura de un narrador omnisciente no implícito para que sea el lector quien se posicione ante los dos grupos de personajes- ha recaído en uno de estos últimos. Es a través de los ojos del médico -único personaje foráneo del relato además de su cochero- desde donde vemos cómo se desarrollan los sucesos. Su pensamiento científico -equiparado al de su paciente- le hará observar los hechos acaecidos con una visión distante y extrañada.

Además, su llegada a la aldea supondrá tanto el comienzo del orden de los hechos del discurso del relato como el inicio temporal de los mismos. Su visión del mundo y de la naturaleza, para él escenario idílico y tranquilo, introduce al lector en un pequeño vecindario galaico, en cuya cercanía se levanta un "cruceiro". Al pasar 
junto a él, y como ya hemos referido, se tropieza con una mociña a la que asusta. Desconcertado por el miedo que ha causado en la chica, la interroga. Ella le cuenta que le ha confundido con un ser maléfico, dotado de un apetito sexual que lo hace temible y salvaje y que ronda los contornos.

Debemos tener en cuenta, para entender el espanto de la chica, que el "cruceiro" es, para el universo mental gallego, un lugar simbólico donde el mundo de los vivos y los muertos, de los entes de carne y hueso y de los seres sobrenaturales se cruzan. Ver allí al doctor, personaje foráneo, de características físicas presumiblemente opuestas a las de los aldeanos hace comprensible la confusión de la "mociña".

Pero el médico está muy lejos de comprender tanto el pensamiento de la chica como sus explicaciones acerca del ente fabuloso que tiene "cuerpo y más alma, como vusté y como yo" -según le relata- y toma a chanza sus palabras. En el diálogo que mantienen, ambos interlocutores comparten mismo el contexto físico y empírico, sin embargo su universo cultural los separa ${ }^{8}$. Él médico no da crédito a las explicaciones de la "mociña", mientras que el lector conoce también la voz interior de la chica mediante el recurso del estilo indirecto libre: "ella sabía lo que sabía y los señores de pueblo no saben nada". También mediante las palabras de este personaje femenino, esta vez en estilo directo, conocemos varios detalles del acoso del supuesto "Rabeno" que Ileva días asediando las parroquias de los contornos y que está siendo perseguido por la guardia.

Una vez en casa de su paciente, el doctor interroga a este convencido de que resolverá sus dudas con una visión racional de los hechos que la mociña le ha narrado. Efectivamente, don Agustín -personaje cuyo nombre siempre va precedido de la partícula "don" que revela un nivel sociocultural y económico más elevado que el del resto de sus vecinos- se extiende en explicarle al médico su interpretación del origen del "Rabeno" y la confusión de los aldeanos al identificarlo con un desconocido que ronda la aldea. Condescendiente con el miedo que provoca entre sus vecinas, dice que el personaje tan sólo se acerca a ellas "con aire de conquistador". Tras esta explicación de Don Agustín no solo se esconde la actitud de un racionalista frente al mito sino que también revela un evidente menosprecio por el temor de las mujeres ante una agresión sexual -como también hiciera el médico- que es lo que a fin de cuentas representa el "Rabeno". Médico y paciente, hombres los dos, están muy lejos de comprender el drama que viven las aldeanas.

Para ellos el "Rabeno" es simplemente un hombre que ha perdido la razón, un demente. Con este juicio representan una tendencia que surgía a fines del siglo XIX y que consideraba a los delincuentes como enfermos que debían ser tratados y ser reinsertados en la sociedad. Antropólogos médicos y juristas comenzaron al mismo tiempo a plantearse si la demencia de los violadores, calificada por una parte de ellos como "demencia moral" podría excusar sus acciones (Bourke 2009: 225) cuestión

8 Escandell Vidal, María Victoria (1996): Introducción a la pragmática, Barcelona, Ariel. 
que generó un amplio debate9 . De acuerdo con esta consideración, el médico, de vuelta a la aldea para esperar a su cochero, decide llamar a las autoridades al día siguiente para que ingresen al desconocido en un asilo. Mientras, se recrea otra vez ante el idílico entorno natural del pueblecillo, que traslada sus pensamientos al mítico pasado donde una vez vivieron felizmente lo sátiros hasta que las leyes humanas obligaron a civilizar su costumbres. Ensimismado en esta visión bucólica de la naturaleza, no se percata de que algo extraño sucede, de que la aldea se halla desierta y de que su cochero se retrasa. Despertando de su ensoñación, sale a buscarlo y lo encuentra en los límites del vecindario presenciando como espectador una brutal escena en la que los personajes de la aldea -el tabernero, su mujer, su hija y una multitud- son los actores principales. Y es que ante la última de las actuaciones del desconocido, del supuesto "Rabeno" que ha intentado, al parecer, agredir a la hija del tabernero, la comunidad aldeana secundada por vecinos de otras parroquias le están propinando una brutal paliza que acabarán con su vida.

Para entender este castigo -a todas luces desproporcionado para el médicotal vez podamos apuntar que las mujeres para cualquier comunidad tradicional gallega significaban uno de sus elementos más preciados ya que de ellas dependía su prolongación. Protegerlas de los ataques sexuales o de otro tipo era tarea, pues, de todos los miembros, que reaccionan infringiendo un castigo proporcional a la gravedad del ataque que recibían ${ }^{10}$.

Precisamente por esta razón los ruegos del médico no son tomados en consideración. Él no es un actor porque ni pertenece ni entiende a los aldeanos, que actúan en su territorio de acuerdo con sus propias leyes. Es tan sólo un espectador, lejano a los hechos y carente de papel en la comunidad. Su intervención no es funcional en el desarrollo de unos hechos que se suceden ante sus ojos como la encarnación de una fantástica leyenda en la que, en términos de Propp una multitud -el héroe-, acaba con el agresor -el "Rabeno"- que ha intentado a atrapar a la princesa -la hija del tabernero.

\footnotetext{
${ }^{9}$ La propia Pardo Bazán critica que, hacia 1890, y a partir de "la libérrima interpretación de los principios de Lombroso" sobre la "afirmación de la irresponsabilidad" por la existencia del "delincuente nato" y del "loco moral", muchos delincuentes fueron exculpados ("La Vida Contemporánea" 8/11/1909, en Pardo Bazán 2005: 402). Entre los más afamados seguidores de Lombroso se encontraba también Enrico Ferri, cuyas obras La Scuda criminale positiva (1885): Napoli, Enrico Detken y Nuevos Estudios de Antropología Criminal ([19--?]): Madrid, La España Moderna, se encuentran entre los fondos de la biblioteca de Emilia Pardo Bazán conservados en la Real Academia Galega.

Io Recordemos, además, que los ataques del "Rabeno", según explica el personaje de la "rapaza" con la que habla el médico, supondrían para las "mociñas nuevas", una "vergüenza" adicional. En las respuestas a la encuesta de 1901 promovida por el Ateneo de Madrid y que llevaba por título Información promovida por la Sección de ciencias morales y políticas del Ateneo de Madrid en el campo de las costumbres populares y en los tres hechos más característicos de la vida: el nacimiento, el matrimonio y la muerte varias de las contestaciones expuestas en el apartado referente a la consideración de la virginidad femenina afirman que la misma era altamente considerada y que en algunos casos su pérdida era o bien una gran obstáculo para contraer matrimonio, o bien motivo de la negación de la dote paterna a la hora de contraer nupcias. (Nacemento, casamento e morte en galicia. Resposta á enquisa do Ateno de Madrid 1990: 88-90).
} 
El relato termina con las imprecaciones de la hija del tabernero que, en medio de una crisis nerviosa, reitera: “¿Quísome coger ese condenado! ¡Agarrome del pelo!". No hay ninguna reflexión final ni del narrador ni de los personajes porque Emilia Pardo Bazán, como hemos dicho, ha querido dejar para el lector la tarea de posicionarse ante los hechos, de comprender o no la conducta de la airada turba y su castigo, o de decantarse hacia las consideraciones del médico y de Don Agustín. Varias dudas surgen en la mente del lector al finalizar el relato: desconocemos si el personaje que finalmente recibe el castigo es en realidad culpable de todos los delitos que los aldeanos le imputan y ni siquiera queda claro cuál es el alcance de estos. Lo realmente importante es que los aldeanos y sus vecinos de los contornos se han sentido amenazados y han acumulado su rabia ante un personaje que supone una amenaza para todos. Ante un agresor común no han escuchado las imprecaciones del médico, quien consideraba al desconocido un demente, ni tampoco han esperado a la justicia representada por la pareja de la Guardia que según la "mociña" le perseguía, sino que han reaccionado ellos mismos, protegiendo así a sus mujeres y propinando al agresor un público y efectivo linchamiento ${ }^{\text {II }}$. Así el "Rabeno", ser maléfico, agresor o loco, no acaba en la cárcel sino en el fondo del mar. La ley institucional no es efectiva porque no llega a solucionar el problema del acosador, ni tampoco el miedo que en las mujeres ha creado un mito que circula como hipotexto por todo el relato. Parece que la escritora, mediante este texto, está denunciando la ineficacia de una justicia insuficiente, que no logra proteger a las mujeres, como muchas veces había denunciado en sus artículos periodísticos. Y que mientras esta no sea del todo efectiva existirán alternativas como la narrada en el cuento.

\footnotetext{
I I En un artículo de La Ilustración Artística datado el 16/11/1901 en el que la escritora refería el caso de una modista violada por dos funcionarios declaraba: "Estimo, sin amarle, al pueblo norteamericano. Grandes fuerzas y grandes energías se desarrollan en su cuerpo joven y robusto. Un de ellas, es a mi ver, la aplicación de la ley de Lynch. Esa ley revela el vigor de ese pueblo. "Que otro haga justicia por mí”, dice el enervado. "Yo me sé hacer justicia", exclama el fuerte apretando los recios puños. En ciertos casos, en ciertos crímenes, en ciertas iniquidades demasiado escandalosas, ¿qué mejor que la ley de Lynch? (...) Así se hace cuando a la facultad de indignación se junta el recurso de la acción, inmmediata y fulminante, propia de hombres resueltos y avezados a defender la vida, a ganarla, a afirmarla contra la naturaleza y los malhechores. Aquí la ley de Lynch no existe (...), ni acaso convendría; pero en el caso de la modistilla, ¡qué simpatica parece la ley de Lynch!”. Unos años más tarde, también en un artículo de La Ilustración Artística del 31/08/190 y aludiendo a la misma ley estadounidense reflexionaba con estas palabras: “¿Qué opinan ustedes de la ley de Lynch? A mí no me disgusta en cuanto revela energías y concepto de la justicia; porque hay crímenes que de tal manera ofenden y soliviantan, que parece que el castigo ha de ser inmmediato, como el golpe con que se responde a grave y bochornosa afrenta. Los que prevalidos de su fuerza atropellan a la niñez; los bestiales ultrajadores de criaturas, ¿merecen acaso otra cosa que el linchamiento? Jamás lo creeré. La indignación del primer instante, que se debiblita después, es la mejor consejera y el juez más recto: en tales casos el sentimiento enseña mejor y guía más certeramente que todas las legalidades formulistas del enjuiciamiento largo y pesado. Y el sentimiento, en hechos como los que frecuentemente narra la prensa, y que por lo general se desenlazan con sobreseimientos o penas leves, dictaría la cuerda, dictaría el garrote, dictaría algo tan ejemplar como lo que practica esa nación fuerte y llena de savia, que ha resuelto el problema de ir a todas partes por el camino más corto". (Ruiz-Ocaña Dueñas 2004a: 238-239).
} 
BIBLIOGRAFÍA

Bajtin, Mijail Mijaïlovich (1991): Teoría y estética de la novela, Trad. Helena S. Kriúkova y Vicente Cazcarra, [Madrid], Taurus.

Bourke, Joanna (2008): Los violadores. Historia del estupro de 1860 a nuestros días, Trad. Enrique Herrando Pérez, Barcelona, Crítica.

Carré Alvarellos, Leandro (s. a.): Apuntes para una mitología popular gallega, Porto, s. n.

Couto Cantero, Pilar (2010-2011): "Análisis y aplicación didáctica del relato de E. Pardo Bazán: «Sin pasión» (1909), en La Tribuna. Cadernos de Estudos da CasaMuseo Emilia Pardo Bazán, pp. 71-96.

Cuestionario do Folclore Galego (1994): [Santiago], Museo do Pobo Galego.

Escandell Vidal, María Victoria (1996): Introducción a la pragmática, Barcelona, Ariel.

Delrío, Martino (1616): Disquisitionum magicarum. Libri sex Venetiis, Vincentium Florinum.

Fernández Flórez, W. (1943): El bosque animado, José Carlos Mainer (ed,), Colección Austral, Edición Espasa Calpe, p. 40.

Gennete, Gèrard (1989): Palimpsestos. La literatura en segundo grado, Madrid, Taurus.

Lisón Tolosana, Carmelo (1971): Antropología cultural de Galicia, Bilbao, Siglo XXI Editores.

Yvancos, José María (1974): "Teoría de la narración", en Darío Villanueva (coord): Curso de teoría de la literatura, Madrid, Taurus.

Herrero Figueroa, Araceli (2010-2011): “Emilia Pardo Bazán. «Feminista: desigualdad intergenérica y maltrato doméstico", en La Tribuna. Cadernos de Estudos da Casa-Museo Emilia Pardo Bazán, pp. 57-70.

Nacemento, casamento e morte en galicia. Resposta á enquisa do Ateno de Madrid, Introd. de Xosé Manuel González Reboredo, Notas de Xosé Ramón Mariño Ferro, A Coruña, Consello da Cultura Galega.

Pardo Bazán, Emilia (1990): Cuentos Completos, Juan Paredes Núñez (ed.), A Coruña, Fundación Pedro Barrié de La Maza.

Pardo Bazán, Emilia (2005): La Vida Contemporánea, Carlos Dorado (ed.), Madrid, Hemeroteca Municipal de Madrid.

Propp, Vladimir (1977): Morfología del cuento, Madrid, Editorial Fundamentos.

Risco, Vicente (1962): “Etnografía. Cultura espiritual”, en Otero Pedrayo, Ramón (dir.): Historia de Galiza, Buenos Aires, Nós, vol. I, pp. 265-779.

Rodríguez González, Eladio (1958-1962): Diccionario enciclopédico gallegocastellano, Vigo, Galaxia. 
Ruiz-Ocaña Dueñas, Eduardo (2004a): La obra periodística de Emilia Pardo Bazán en la Ilustración Artística de Barcelona (1895-1896), Madrid, Fundación Universitaria Española.

Ruiz-Ocaña Dueñas, Eduardo (2004b): “Emilia Pardo Bazán y los asesinatos de mujeres", en Didáctica (Lengua y Literatura), 16, pp. 177-188. 